\title{
Ionized Calcium and Serum Electrolytes Profile in Captive Asian Elephants (Elephas maximus) of Tamil Nadu, India
}

\author{
M. Veeraselvam, P. Selvaraj, S. Senthil Kumar, A. Senthilkumar,
}

C. Sreekumar, T.M.A. Senthilkumar, N. Premalatha

10.18805/IJAR.B-4783

\begin{abstract}
Background: Serum electrolyte monitoring is essential in the health assessment of captive elephants. The major elements of calcium, sodium, potassium, chloride and bicarbonate are playing a major role in regulation of nerve and muscle functions and in maintaining acid base and water balance. Excess levels or loss of particular electrolytes may occur as secondary changes caused by certain diseases or changes in physiological regulations. The aim of this study was to evolve the baseline reference values for serum electrolyte levels in captive Asian elephants raised in Tamil Nadu state of India.

Methods: As part of the periodical health assessment blood samples were collected from auricular vein for 42 apparently healthy captive Asian elephants in Tamil Nadu, India. Serum electrolyte levels such as sodium $\left(\mathrm{Na}^{+}\right)$, potassium $\left(\mathrm{K}^{+}\right)$, chloride $\left(\mathrm{Cl}^{-}\right)$, ionized calcium (iCa), non-ionized calcium and total calcium ( $\mathrm{tCa}$ ) were determined by using an automated electrolyte analyzer.

Result: Most of the ranges of electrolyte values observed in this study were similar to that of previous reports. As not much studies on ionized calcium are available on captive Asian elephants the value of ionized calcium found this study $1.16 \pm 0.13 \mathrm{mmol} / \mathrm{L}$ could serve as reference. There was no much variation observed in various age groups. This electrolyte profile values will serve as baseline values to evaluate the health and clinical conditions of captive elephant populations.
\end{abstract}

Key words: Asian elephant, Electrolytes, lonized calcium.

\section{INTRODUCTION}

India has a long fascinating history of domesticating wild elephants. Captive Asian elephants have been very closely associated and deeply entwined with the religion, myths and cultural heritage of India for centuries (Kumar et al., 2019). Elephants have adapted to a wide variety of environments in captive conditions. Maintaining of psychological and physiological wellbeing of elephants is one of the most important objectives in captive conditions. The health status of captive elephants depends on various factors including husbandry management, nutrition and infectious and noninfectious diseases (Mikota et al., 1994; Sadler, 2001; Clauss and Kiefer, 2003; Schmitt, 2003). Changes in environmental, social, physical, physiological and psychological factors in captive conditions can modify the homeostasis of individual elephants and lead to a range of health issues that could contribute to significant morbidity and mortality in elephants. Elephants are prone to a variety of infectious and noninfectious diseases; but recognizing that they are even sick may be difficult and challenging (Miller and Fowler, 2015). Elephants often do not manifest clinical signs of illness until disease is well advanced. Such masking of clinical signs makes identifying and treating diseases in elephants as very challenging for veterinarians and zoo managers. Clinical pathological examination including haematology, serum biochemistry and electrolyte values are most often the ell valuable diagnostic tools for elephants, especially when clinical signs were nonspecific and other diagnostic techniques may not be available for immediate applications (Fowler and Mikota, 2006).
Department of Wildlife Science, Madras Veterinary College, Tamil Nadu Veterinary and Animal Sciences University, Vepery, Chennai600 007, Tamil Nadu, India.

Corresponding Author: P. Selvaraj, Department of Wildlife Science, Madras Veterinary College, Tamil Nadu Veterinary and Animal Sciences University, Vepery, Chennai-600 007, Tamil Nadu, India. Email: drdvmselvaraj3@gmail.com

How to cite this article: Veeraselvam, M., Selvaraj, P., Kumar, S.S., Senthilkumar, A., Sreekumar, C., Senthilkumar, T.M.A., Premalatha, N. (2022). Ionized Calcium and Serum Electrolytes Profile in Captive Asian Elephants (Elephas maximus) of Tamil Nadu, India. Indian Journal of Animal Research. DOI: 10.18805/ IJAR.B-4783.

Submitted: 22-09-2021 Accepted: 23-12-2021 Online: 20-01-2022

Serum electrolyte concentrations provides important information especially in relation to the respiratory, renal, digestive and endocrine systems and are helpful to differentiate the diseased animals from healthy individuals (Bouda et al., 2000). The major elements of calcium, sodium, potassium, chloride and bicarbonate are playing a major role in regulation of nerve and muscle functions and in maintaining acid base and water balance. Excess levels or loss of particular electrolytes may occur as secondary changes caused by certain diseases or changes in physiological regulations. Marked disturbances in electrolyte concentrations were often associated with death in critically ill patients due to the impacting consequences in acid-base status, regulation of membrane potential, 
Ionized Calcium and Serum Electrolytes Profile in Captive Asian Elephants (Elephas maximus) of Tamil Nadu, India

nerve and muscle contraction and function of enzyme systems (Goggs et al., 2017).

The serum sodium concentration is an indication of the amount of water in the extracellular fluid (DiBartola, 2012). Animals with hyponatremia or hypernatremia may have decreased or increased total body sodium content. The changes of sodium concentration reflect the abnormalities in water balance (Goggs, 2017). While severe alterations in sodium concentration were associated with considerable morbidity and mortality even mild hyponatreamia was also found to be associated with worse outcomes especially when it complicates conditions such as heart failure (Reynolds et al., 2006). Acid-base balance and osmolality were maintained by regulation of serum chloride concentration. Disturbances in chloride level causes metabolic acidosis or alkalosis in animals (Ha et al., 2013). Potassium being the most abundant intracellular cation ( $>98 \%$ ) of the body, kidney plays a major role in the maintenance of potassium homeostasis. Disorders of potassium levels were associated with a risk of death in animals, particularly hyperkalemia cause death in veterinary patients with renal injury, urinary tract obstruction and hypoadrenocorticism (Goggs et al., 2017a). Calcium being an extracellular cation, is distributed in free and ionized form and has important roles in neural function, blood coagulation, muscle contractility and also as cofactor in numerous enzymatic reactions (Fowler and Mikota, 2016). Low calcium was found to be associated with dystocia in captive Asian elephants, by causing failure in initiation of second stage of labour (Aroch et al., 2016).

In elephant medical practices the evaluation of serum electrolytes is considered useful for early diagnosis of diseases, treatment and reproductive stage and detect general welfare of elephants (Wijesekera et al., 2008; Pandit et al., 2015). Although several studies have been extensively studied on serum biochemical and mineral status in Asian elephants (Dagolla et al., 2004) only a few studies have addressed on electrolyte levels in Asian elephants (Wijesekera et al., 2008). The aim of this study was to evaluate and document the baseline reference ranges for serum electrolyte levels in captive Asian elephants in Tamil Nadu, India.

\section{MATERIALS AND METHODS}

Periodical veterinary assessment of captive elephants is routinely done by the author's team. Clinical examination of elephants was done as per the standard protocols
(Ramanathan and Mallapur, 2008; Fowler and Mikota, 2016; Jayaprakash, 2018). A total of 42 Asian elephant serum samples were utilized for assessment of electrolytes in this study. The age of elephants in this study ranged from 15 years to 62 years and all the elephants were apparently healthy during the study period from August 2020 to April 2021. During sampling, the animals were made into lateral recumbency with the help of its care takers and blood was collected from auricular vein into plain tubes. The blood was allowed to clot at room temperature and serum was separated within 2 hours of collection by centrifugation at $2000 \mathrm{rpm}$ for 2 minutes. The serum was stored at $-20^{\circ} \mathrm{C}$ until the electrolytes were determined. Serum electrolytes sodium, potassium, chloride, ionized calcium, non-ionized calcium levels were determined by using an automated electrolyte analyzer (Allcare 9000 series electrolyte analyzer) using the manufacturer recommended kits as per standard protocols used for veterinary studies (Yogeshpriya et al., 2017) at Veterinary College and Research Institute, Orathanadu. Collected data were subjected to descriptive statistics by Student's t-test (Snedecor and Cochran, 1967 ) and reference intervals with 95\% confidence interval and $99 \%$ confidence interval for each parameter were also calculated.

\section{RESULTS AND DISCUSSION}

The results of mean value, standard deviation, lower and upper value and $95 \%$ confidence interval for serum electrolytes were shown in Table 1. The observed sodium values were $128 \pm 0.79 \mathrm{mmol} / \mathrm{L}$, chloride $89.81 \pm 12 \mathrm{mmol} / \mathrm{L}$, Potassium $5.28 \pm 0.79 \mathrm{mmol} / \mathrm{L}$. The observed ionized calcium was $1.16 \pm 0.13 \mathrm{mmol} / \mathrm{L}$ and total calcium was $2.38 \pm 0.20 \mathrm{mmol} /$ L. Analysis of results showed not much variation observed among various age groups of captive Asian elephants.

Health management of captive elephants is always challenging task. Many a time sickness is not even deducted, as elephant don't manifest unless very advanced disease status is present. Periodical haemato-biochemical testing is generally helping in some ways. Electrolyte monitoring helps in identification of many diseases. Electrolytes are very much essential for normal biochemical and physiological functions of the body (Kaneko et al., 2008), including on maintaining hydration status, acid- base balance, generating and conducting action potentials in the nerves and muscles, maintenance of proper blood $\mathrm{pH}$

Table 1: The mean value, standard deviation, lower and upper value and 95\% confidence interval for serum electrolytes in 42 captive elephants.

\begin{tabular}{lcccccc}
\hline Parameters & Mean & $\begin{array}{c}\text { Standard } \\
\text { deviation }\end{array}$ & $\begin{array}{c}\text { Maximum } \\
\text { value }\end{array}$ & $\begin{array}{c}\text { Minimum } \\
\text { value }\end{array}$ & $\begin{array}{c}95 \% \text { confidence } \\
\text { interval }\end{array}$ & $\begin{array}{c}99 \% \text { confidence } \\
\text { interval }\end{array}$ \\
\hline Sodium (mmol/L) & 128.00 & 0.79 & 138.9 & 120.6 & $126.66-129.34$ & $126.24-129.76$ \\
Chloride (mmol/L) & 89.81 & 12.00 & 105.5 & 61.60 & $86.13-93.43$ & $85.04-94.57$ \\
Potassium (mmol/L) & 5.28 & 0.79 & 7.71 & 3.89 & $5.04-5.51$ & $4.96-5.94$ \\
lonized calcium (mmol/L) & 1.16 & 0.13 & 1.47 & 0.88 & $1.12-1.19$ & $1.10-1.21$ \\
Non-ionized calcium (mmol/L) & 1.20 & 0.11 & 1.42 & 0.93 & $1.16-1.23$ & $1.15-1.24$ \\
Total calcium (mmol/L) & 2.38 & 0.20 & 2.7 & 1.86 & $2.31-2.44$ & $2.30-2.45$ \\
\hline
\end{tabular}


(Bradbury, 1973; Goggs et al., 2017). Serum electrolyte concentrations are responsible for maintaining the balance of fluids between the intracellular and extracellular environments. Hence, it is important to detect the changes in electrolyte concentrations and monitor them very frequently for the animals especially those with a dynamic illness, so that these alterations can be treated prior to the situation becoming more severe or life threatening. In this present study these levels are indicative of the health status of the studied elephants.

Mean levels of $\mathrm{Na}^{+}$in this study was $128.0 \pm 0.79 \mathrm{mmol} /$ Land it was within the reference values reported earlier by Fowler and Mikota (2006) in elephants (120-140 mEq/L), however the observed values were slightly higher than the values reported by Brown et al. (1994) in African elephants $(103 \pm 1.8 \mathrm{mmol} / \mathrm{L})$. The variations in Serum $\mathrm{Na}^{+}$levels between the individual elephants could possibly be related to their drinking habit, water quality, feeding behaviour, exercise and social interaction in captive conditions. Brown et al. (1994) reported that the variations in sodium concentrations were attributed to variations in water intake and forage availability. Chamaille-Jammes et al. (2007) opined that elephant distribution was having strong relationship with sodium rich water holes, forage availability around waterholes as well as their daily ranging behavior and social interactions. The observed sodium levels in this study indicated that all the captive elephant are healthy, in terms of sodium status.

Serum chloride $\left(\mathrm{Cl}^{-}\right)$anion is essential to the normal function of all cells and has a crucial role for the maintenance of osmolality and for acid-bas balance (Goggs et al., 2017). Chloride levels reported in this study $(89.81 \pm 12 \mathrm{mmol} / \mathrm{L})$ was found to be comparatively lower than the values reported in elephants (100-115 mEq/L) by Fowler and Mikota (2006). Lower values were considered to be associated with the age of elephants as well as differences in feeding pattern under captive conditions. Allen et al. (1985) observed of age-related differences in chloride levels in African elephants. These levels in this study could possibly be due to the variations in water intake, water quality as well as gastrointestinal health of these elephants. Even a mild secretory diarrhea can change chloride levels. However, these levels were not so low to call them as hypochloreamic.

Serum potassium $\left(\mathrm{K}^{+}\right)$is the major intracellular cation, essential to the normal function of all cells and it has critical role in neuromuscular and cardiac excitability. Mean serum potassium levels observed in this study was $5.28 \pm 12 \mathrm{mmol} / \mathrm{L}$ and it was similar to the mean value of $3.0-6.0 \mathrm{mEq} / \mathrm{L}$ reported by Fowler and Mikota (2006). However, the values found in this study was higher than the values reported by Brown et al. (1994) in African elephants and lower than the values reported by Silva and Kuruwita (1993) in Asian elephants in Sri Lanka. These variations of the levels in these studies could possibly be due to the diet compositions in captive conditions and also possibly be due to the physiological differences on species and as subspecies levels (Wijesekera et al., 2008).
The overall mean values of ionized calcium, non-ionized calcium, total calcium in this study were $1.16 \pm 0.13 \mathrm{mmol} / \mathrm{L}$, $1.20 \pm 0.11 \mathrm{mmol} / \mathrm{L}$ and $2.38 \pm 0.20 \mathrm{mmol} / \mathrm{L}$ respectively. The total calcium levels were lower than the values reported by Brown et al. (1994) in African elephants and those reported by Wijesekra et al. (2008) in captive Asian elephants in Sri Lanka. These differences may be related to the amount of calcium in their diet as well as their metabolism in elephants. Sonsbeek et al. (2013) observed that the dietary calcium levels played a superior role in plasma calcium concentration and found that the oral calcium and cholecalciferol supplementations resulted in a significant increase in plasma total calcium concentration. Brown and White (1977) opined that the variety of diet and seasonal variations affected the intestinal absorption and serum levels of calcium in elephant.

The ionized calcium concentration observed in this study was similar to those reported by Aroch et al. (2016), who had reported the value of $1.16 \pm 0.20 \mathrm{mmol} / \mathrm{L}$ as the mean concentration of serum ionized calcium values in four captive Asian elephant cows. Fowler and Mikota (2006) observed that ionized calcium generally remained normal even when total calcium was altered by changes in protein levels. In another study, Kolk et al. (2008) reported a lower value $(0.93 \pm 0.11 \mathrm{mmol} / \mathrm{L})$ in four Asian elephants. Such variations found in these elephants could possibly be due to the food quality and stable food availability in captive conditions in different areas. These 42 elephants in this study were found to be healthy and hence the comparatively larger sample size associated results for electrolytes could well serve as a reference range for assessing the health and disease of captive Asian elephants.

\section{CONCLUSION}

The serum electrolytes values were evaluated in 42 apparently healthy captive Asian elephants. Most of the ranges of electrolyte values were similar to that of previous reports. All the values of ionized calcium as well as serum electrolyte profile in this study was found to be within the normal ranges and indicated the overall healthiness of 42 captive elephants. This information from larger sample size of 42 captive elephants presents a more authentic value and may be used as reference range to evaluate the health and clinical conditions of captive elephant populations. Variations in some values might occur due to the prevailing nutritional and environmental factors as well as daily ranging behavior and social interaction of elephants. Ionized calcium of these 42 elephants indicated that there was overall good musculoskeletal health. In addition, maintenance of the health of these 42 captive elephants was good as was represented by these electrolyte profiles.

\section{ACKNOWLEDGEMENT}

The authors thank the Dean, Faculty of Basic Sciences and the Dean, Veterinary College and Research Institute, Orathanadu, the Professor and Head, Centralized Clinical Laboratory, Madras Veterinary College for their support and 
assistance. Authors also thank the various institutions and individuals who maintained these captive elephants and also the handlers of these elephants.

\section{REFERENCES}

Allen, J.L., Jacobson, E.R., Harvey, J.W., Boyce, W. (1985). Hematologic and serum chemical values for young African elephants (Loxodonta africana) with variations for sex and age. Journal of Zoo and Wildlife Medicine. 16: 98-101.

Aroch, I., Larian, N., Anvi-Magen, N. (2016). Concentrations of Free (lonized) and Total Calcium and Magnesium in Healthy captive Asian Elephants (Elephas maximus) and Effects of ample type and $\mathrm{pH}$ on measured Free calcium and magnesium concentrations. Israel Journal of Veterinary Medicine. 71: 24-32.

Bouda, J., Davalos-Flores, L., Nunez-Ochoa, N., Paasch-Martinez, L., Quiroz-Rocha, G.F. (2000) Blood acid-base and serum electrolyte values in red deer (Cervus elephus). Canadian Journal of Veterinary Research. 64: 222-225.

Bradbury, W.B., Anaesth, B.J. (1973). Physiology of body fluids and electrolytes. British Journal of Anaesthesia. 45: 937.

Brown, I.R.F., White, P.T. (1977). Serum calcium, magnesium, phosphorus and alkaline phosphatase in the African Elephant, Loxodonta Africana. Comparative Biochemistry and Physiology. 56: 159-162.

Brown, J.L., Schoenemann, H.M., Raath, J.P., Vos, V.D., Bush, M. (1994). Serum concentrations of cationic minerals in Freeranging elephants (Loxodonta Africana) in the Kruger National Park. Journal of Zoo and Wildlife Medicine. 25: 495-499.

Chamaille-Jammes, S., Fritz, H., Holdo, R.M. (2007). Spatial relationship between elephant and sodium concentration of water disappears as density increases in Hwange National Park, Zimbabwe. Journal of Tropical Ecology. 23: 725-728.

Clauss, M., Kiefer, B. (2003). Digestive acidosis in captive wild herbivores: Implications for hoof health. Verh.ber Erkrg Zootiere. 41: 57-70.

Dangolla, A., Malitha, A.G., Silva, I. (2004). Mineral status in Blood serum of Domesticated elephants (Elephants maximus) and certain plants of Sri Lanka. Zoos' Print Journal. 19: 1549-1550.

Dibartola, S.P. (2012). Fluid, Electrolytes and Acid-Base Disorders in Small Animal Practice, $4^{\text {th }}$ ed., Saunders Publication.

Fowler, M.E. and Mikota, S.K. (2006). Elephant Biology, Medicine and Surgery, $1^{\text {st }}$ ed. Blackwell Publishing Asia, Victoria 3053, Australia.

Goggs, R., DeRosa, S., Fletcher, D.J. (2017). Electrolyte Disturbances are associated with Non-survival in Dogs - A Multivariable analysis. Frontiers in Veterinary Science. 4: 1-11.

Ha, Y.S., Hopper, K., Epstein, S.E. (2013). Incidence, Nature and Etiology of Metabolic Alkalosis in Dogs and Cats. Journal of Veterinary Internal Medicine. 27: 847-853.

Jayaprakash, G. (2018). Surgical Removal of Unshed Molar Tooth in an Asian Elephant (Elephas maximus). $10^{\text {th }}$ Clinical Case Conference on Farm and Companion Animal Practice for Veterinary Students, Tamil Nadu Veterinary and Animal Science University, Chennai.
Kaneko, J.J., Harvey, J.W., Bruss, M.L. (2008). Clinical Biochemistry of Domestic Animals, Sixth ed. Academic, London, pp. 117-138.

Kolk, J.H.V.D., Leeuwen, J.P.T.M.V., Belt, A.J.M.V.D., Schaik, R.H.N.V., Schaftenaar, W. (2008). Subclinical hypocalcemia in captive Asian elephants (Elephas maximus). Veterinary Record. 162: 475-479.

Kumar, N., Natarasan, K., Sugumar, K., Kumar, V.S., Velmurugan, R., Shanmugasundaram, P. (2019). Therapeutic management of Wounds in Asian elephants. Drug Invention Today. 11: 237-240.

Mikota, S.K., Sargent, E.L., Ranglack, G.S. (1994). Medical Management of the Elephant. West Bloomfield Michigan, Indira Publishing House. pp. 1-298.

Miller, R.E., Fowler, M.E. (2015). Fowler's Zoo and Wild Animal Medicine, $8^{\text {th }}$ Volume, Elsevier Saunders, St. Luis, Missouri.

Pandit, A., Dhakal, I.P., Gairhe, K.P., Rana, H.B. (2015). Serum biochemical profile of the elephants in Chitwan District, Nepal. International Journal of Recent Scientific Research. 6: 3130-3135.

Ramanathan, A., Mallapur, A. (2008). A visual health assessment of captive Asian Elephants (Elephas maximus) housed in India. Journal of Zoo and Wildlife Medicine. 39: 148-154.

Reynolds, R.M., Padfield, P.L., Seckl, J.R. (2006). Disorders of sodium balance. British Medical Journal. 332: 702-705.

Sadler, W.C. (2001). The Role of Nutrition and Possible Impact on Elephant Foot Care. In: The Elephants Foot, [Csuti, B., Sergent, E.L., Bechert, U.S. editors]. lowa State University Press, lowa, pp. 13-15.

Sakals, S., Peta, H.G.R., Fernandez, N.J., Allen, A.L. (2006). Determining the cause of hypercalcemia in a dog. Canadian Veterinary Journal. 47: 819-821.

Schmitt, D.L. (2003). Proboscidea (elephants). In: Zoo and Wild Animal Medicine, [Fowler, M.E., Miller, R.E., editors]. New York, Elsevier Science USA. pp. 541-550.

Silva, I.D., Kuruwita, V.Y. (1993). Hematology, plasma and serum biochemistry values in domesticated elephants (Elephas maximus ceylonicus) in Sri Lanka. Journal of Zoo and Wildlife Medicine. 24: 440-444.

Snedecor, G.W., Cochran, W.G. (1967). Statistical Methods, $8^{\text {th }}$ Ed. lowa State University Press, lowa.

Sonsbeek, G.R.V., Vander Kolk, J.H., VanLeeuwen, J.P.T.M., Marais, J., Schaftenaar, W. (2013). Effect of calcium and cholecalciferol supplementation on several parameters of calcium status in plasma and urine of captive Asian (Elephas maximus) and African elephants (Loxodonta africana). Journal of Zoo and Wildlife Medicine. 44: 529-540.

Wijesekera, R.D., deAlwis, G.K.H., Vithana, D., Ratnasooriya, W.D. (2008). Serum levels of some electrolytes of captive Sri Lankan Elephants. Gajah. 29: 24-27.

Yogeshpriya, S., Saravanan, S., Ranjithkumar, M., Sivakumar, M., Arulkumar, T., Jayalakshmi, K., Veeraselvam, M., Krishna kumar, S., Selvaraj, P. (2017). Haemato-biochemical and electrolyte alterations in naturally occurring theileria associated bovine anaemia (Taba). Journal of Animal Health and Production. 5: 64-67. 